\title{
Presentación
}

La Convención Americana sobre Derechos Humanos permite a los Estados miembros de la Organización de Estados Americanos consultar a la Corte Interamericana acerca de la interpretación de la propia Convención o de otros tratados concernientes a la protección de los derechos humanos en los Estados americanos. La Convención establece, de este modo, la denominada competencia consultiva de la Corte Interamericana, que ha de servir para clarificar las obligaciones de los Estados americanos en materia de derechos humanos con independencia de la existencia de una controversia concreta (como sucede en el caso de la competencia contenciosa).

El 30 de mayo de 2018, la Corte Interamericana emitió su Opinión Consultiva número 25, relativa a la institución del asilo diplomático. La Opinión había sido solicitada por Ecuador y tenía como trasfondo la protección que este país había otorgado, en su sede diplomática en Londres, al señor Julián Assange. Ecuador pretendía que la Corte clarificara el régimen legal del asilo a la luz del derecho internacional de los derechos humanos. También buscaba, indirectamente, que la Corte se pronunciara sobre las obligaciones del Estado territorial (en este caso, el Reino Unido) en caso de asilo diplomático.

La Corte respondió la primera petición declarando que la variante diplomática no se encontraba incluida en las disposiciones de la Convención Americana y de la Declaración Americana sobre el asilo. Así, pues, no hay un derecho amparado por estos instrumentos a recibir asilo diplomático. Por otra parte, la Corte contestó la segunda petición aclarando que la respuesta que daba solo era aplicable a los Estados que fueran parte de la Organización de los Estados Americanos, ya que ella no tiene competencia para referirse a las obligaciones de Estados ajenos a este sistema.

El número de la revista Precedente que aquí se presenta está orientado principalmente a estudiar, a través de cuatro trabajos de investigación, la Opinión Consultiva 25. El trabajo de Diego Molina Conzué aborda los aspectos conceptuales, diferenciando entre el asilo diplomático, el asilo territorial y el refugio e indicando cuál es el encaje de estas figuras bajo los instrumentos interamericanos. También se refiere a la relación de estos institutos con el principio de no devolución, piedra angular del régimen de protección internacional. 
El artículo de Fernando Arlettaz coloca la Opinión Consultiva en la línea de la jurisprudencia previa de la propia Corte Interamericana. Señala que la Corte insiste en su problemática afirmación de que la Convención y la Declaración americanas consagran un verdadero derecho individual a recibir asilo territorial. Aunque el asilo diplomático no esté incluido en los instrumentos interamericanos, por aplicación del principio de no devolución, los Estados deben abstenerse de entregar a las personas que lo solicitan cuando exista un riesgo para su vida o libertad. El artículo señala, no obstante, que no surge claramente de la Opinión Consultiva cuáles son las obligaciones del Estado territorial ante el otorgamiento del asilo diplomático o la abstención de entrega basada en el principio de no devolución.

El texto de Andrea Pinto Oliveira vuelve sobre el principio de no devolución para señalar su vinculación con la eficacia extraterritorial de los derechos humanos según el punto de vista del tribunal interamericano. La autora defiende que, ante la amplitud de los efectos extraterritoriales que este tribunal reconoce al principio de no devolución, la figura del asilo diplomático resulta superada.

Finalmente, el texto de Encarnación La Spina coloca el asilo diplomático en una perspectiva comparada americano-europea. En este sentido, la autora afirma que el asilo diplomático tiene un difícil encaje en el sistema europeo común de asilo, aunque podría ser una ventana de oportunidad ante las fisuras europeas de los mecanismos de protección internacional en casos de urgencia humanitaria. El artículo analiza las peculiaridades y diferencias del asilo diplomático con otras figuras aparentemente afines y explora en clave crítica las oportunidades y los límites que plantea para el sistema europeo común de asilo.

El número de la Revista se completa con otros tres trabajos ajenos a su núcleo monográfico. Javier Espinoza de los Monteros Sánchez se refiere a la universalidad de los derechos humanos. Afirma que esta universalidad es predicable de la forma pero no del contenido de esos derechos. Adoptando la perspectiva teórica de Niklas Luhmann y Raffaele Di Giorgi, pone de manifiesto que, al carecer de contenidos universales, los derechos humanos no pueden considerarse como un límite objetivo frente a la producción legislativa y que tal límite es, en realidad, construido por los jueces constitucionales.

Andrés Botero Bernal presenta una investigación histórica sobre la eficacia de la normativa sobre caminos en la Antioquía del siglo XIX. Estudia tres casos (la primera república de 1811 a 1815, la normativa de la Cámara provincial entre 1848 y 1851 y la legislación estatal entre 1856 y 1886) que, según señala, 
muestran la conformación de un cuerpo jurídico altamente complejo en su estructura formal, pero ineficaz en la práctica. Para explicar esta situación recurre a una alegoría psicoanalítica: la existencia de una neurosis obsesivocompulsiva que lleva a un síndrome normativo en el que destaca la eficacia simbólica del derecho.

Por último, Sergio Castillo Galvis analiza la posición de la Corte Constitucional y el Consejo de Estado frente al ejercicio del control de convencionalidad en el contexto de terminación del conflicto armado en Colombia. Propone dos grandes categorías: las generalidades del control de convencionalidad como obligación estatal internacional y la posición específica de las altas cortes en relación con la concepción y el ejercicio del control. El autor aplica la técnica del análisis de contenido y concluye que existe una divergencia entre la concepción que del mecanismo interamericano posee la Corte Constitucional y la que tiene el Consejo de Estado.

\section{Fernando Arlettaz}

Consejo Nacional de Investigaciones Científicas y Técnicas

Universidad de Buenos Aires, Argentina 